\title{
European Union
}

\section{"SBS Belgium"}

\section{Decision of the European Court of Justice (Ninth Chamber) 19 November 2015 - Case No. C-325/14}

\section{SBS Belgium NV v. Belgische Vereniging van Auteurs, Componisten en Uitgevers (SABAM)}

Directive 2001/29/EC, Art. 3(1)

Keywords Communication to the public - Distribution of television programmes Direct injection

1. Article 3(1) of Directive 2001/29/EC of the European Parliament and of the Council of 22 May 2001 on the harmonisation of certain aspects of copyright and related rights in the information society, must be interpreted as meaning that a broadcasting organisation does not carry out an act of communication to the public, within the meaning of that provision, when it transmits its programme-carrying signals exclusively to signal distributors without those signals being accessible to the public during, and as a result of that transmission, those distributors then sending those signals to their respective subscribers so that they may watch those programmes, unless the intervention of the distributors in question is just a technical means, which it is for the national court to ascertain. 